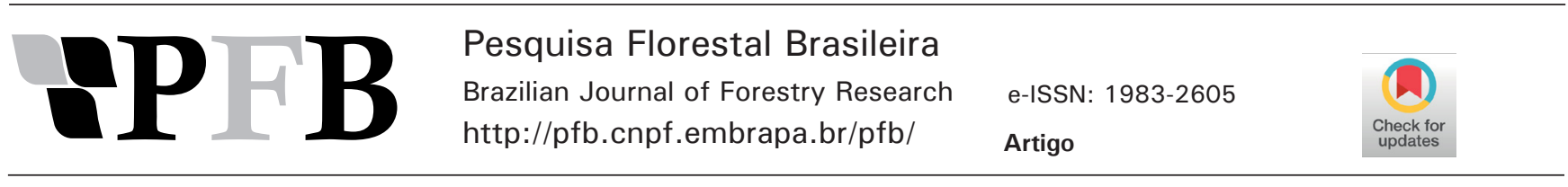

\title{
Estabelecimento de Anadenanthera colubrina var. cebil sob inoculação micorrízica e fertilização no Pantanal brasileiro
}

\author{
Márcia Toffani Simão Soares ${ }^{1}$ (D), Fernando Antonio Fernandes²(D), Gustavo Ribas Curcio ${ }^{1}$ (D), Gustavo Menezes ${ }^{3}$ (D), \\ Alexander Silva de Resende ${ }^{4}$ (D), Sérgio Gaiad ${ }^{1}$ (D), Shizuo Maeda ${ }^{1}$ (D), Marcos Silveira Wrege ${ }^{1}$ (D) \\ ${ }^{1}$ Embrapa Florestas, Estrada da Ribeira, Km 111, C.P. 319, CEP 83411-000, Colombo, PR, Brasil \\ Embrapa Pantanal, Rua 21 de Setembro n. 1880, C.P. 109, CEP 79320-900, Corumbá, MS, Brasil \\ ${ }^{3}$ Guará Serviços Ambientais e Produção Vegetal. Rua Colombo n. 621, CEP: 79302-080, Corumbá, MS, Brasil \\ ${ }^{4}$ Embrapa Agrobiologia, Rodovia BR-465, Km 7 - Antiga Rodovia Rio-São Paulo, CEP 23891-000, Seropédica, RJ, Brasil
}

"Autor correspondente:

marcia.toffani@embrapa.br

Termos para indexação:

Espécie nativa

Estresse abiótico

Micorriza

Index terms:

Native species

Abiotic stress

Mycorrhiza

Histórico do artigo:

Recebido em 21/06/2020

Aprovado em 10/09/2021

Publicado em 13/12/2021

\section{(c) (1) $\Theta \Theta$}

https://doi.org/10.4336/2021.pfb.41e202002129
Resumo - Este trabalho objetivou avaliar o estabelecimento de Anadenanthera colubrina (Vell.) Brenan var. cebil [Griseb.] Altschul sob inoculação micorrízica e fertilização no Pantanal da Nhecolândia, MS. O experimento foi implantado em março de $2015 \mathrm{em}$ ambiente de cordilheira parcialmente desmatada, em blocos ao acaso distribuídos no micro relevo, e parcelas subdivididas. Os principais tratamentos foram constituídos por mudas submetidas ou não (controle) à inoculação mista com Rhizophagus clarus e Gigaspora margarita, e aos tratamentos secundários de adubação com doses de sulfato de amônio e cloreto de potássio. Entre 2015 e 2017 foram avaliados a abertura do dossel das árvores remanescentes, o percentual de sobrevivência e o crescimento de A. colubrina. Melhores condições de sobrevivência foram verificadas na porção da cordilheira mais próxima à baía, sob sombreamento moderado e com a aplicação, no plantio, de $15 \mathrm{~g}$ de sulfato de amônio e de $5 \mathrm{~g}$ de cloreto de potássio por muda. A inoculação micorrízica promoveu incremento de $16 \%$ em diâmetro do colo aos 23 meses de idade, não aumentando a sobrevivência da espécie. Estudos complementares são necessários para subsidiar estratégias de manejo de $A$. colubrina, em condições de plantio no Pantanal da Nhecolândia.

\section{Establishment of Anadenanthera colubrina var. cebil under mycorrhizal inoculation and fertilization in Brazilian Pantanal}

\footnotetext{
Abstract - This study aimed to evaluate the establishment of Anadenanthera colubrina (Vell.) Brenan var. cebil [Griseb.] Altschul inoculated with mycorrhizal fungi and fertilized in the Pantanal of Nhecolândia, Mato Grosso do Sul State, Brazil. The experiment was established in March 2015 in a deforested "cordilheira" environment, in randomized blocks distributed in micro-relief, with subdivided plots. The main treatments corresponded to seedlings submitted or not (control) to Rhizophagus clarus and Gigaspora margarita mixed inoculation. The secondary treatments were doses of ammonium sulfate and potassium chloride fertilizers. We monitored from 2015 to 2017 the plants the plants under shading from the presence of remnant tree after deforestation, as well as the percentage of survival and growth parameters of $A$. colubrina. The best survival condition occurred in the portion of relief adjacent to the freshwater lake, under moderate shading, with the application at planting of $15 \mathrm{~g}$ of ammonium sulfate and $5 \mathrm{~g}$ of potassium chloride per plant. Mycorrhizal inoculation promoted $16 \%$ increase in diameter at 23 months of age, not increasing the species survival. We recommend complementary studies to support management strategies of $A$. colubrina under planting conditions in the Brazilian Pantanal.
} 


\section{Introdução}

Programas de reflorestamento com essências florestais nativas de interesse econômico são fundamentais para diminuir a pressão sobre populações naturais (Scarante et al., 2017; Machado et al., 2018; Wilson et al., 2019), ampliar a capacidade de resiliência dos sistemas de produção (Locatelli et al., 2015; Kongsager et al., 2016; Bustamante et al., 2019) e adequar o espaço rural a critérios estabelecidos em acordos multissetoriais e na legislação vigente (Brasil, 2013, 2015; Metzger et al., 2019. A escassez de informações consolidadas sobre desempenho silvicultural, como potencial produtivo, tolerância a estresses abióticos (Alves \& Karvatte Junior, 2019) e exigências nutricionais restringe significativamente ações voltadas à conservação e ao uso econômico destas espécies (Nascimento et al., 2012; Machado et al., 2018).

$\mathrm{O}$ angico vermelho (Anadenanthera colubrina (Vell.) Brenan var. cebil [Griseb.] Altschul (Fabaceae, Mimosoideae) apresenta ampla ocorrência natural no país, destacando-se por possuir a maior abrangência geográfica dentre as espécies do gênero (Carvalho, 2003). Na planície pantaneira, ocorre em matas semidecíduas e cerradões situados em "cordilheiras", pequenas faixas de terreno não inundável, com $1 \mathrm{~m}$ a $3 \mathrm{~m}$ acima do relevo adjacente (Mercante et al., 2011), coberta por vegetação arbórea (cerrado, cerradão ou mata, Salis et al., 2006). A espécie se destaca quanto ao potencial de uso múltiplo, como a recomposição de cobertura florestal (Isernhagen, 2015) e de ecossistemas degradados (Martinotto et al., 2012; Carnevali et al., 2016), para obtenção de madeira (Lima et al., 2016) e compostos medicinais (Soldati \& Albuquerque, 2010; Pessoa et al., 2012; Barreto et al., 2016).

Em regiões de maior fragilidade ambiental, como o Pantanal brasileiro, a adaptação de técnicas voltadas à silvicultura de espécies nativas envolve o enfrentamento de desafios de alta complexidade. A região é caracterizada pela sazonalidade climática, temperaturas extremas e ocorrência de unidades pedológicas suscetíveis a processos hidromórficos (Soares et al., 2017a). Embora a oferta de nutrientes (Gonçalves et al., 2008; Freitas et al., 2015) e a simbiose micorrízica (Singh \& Gogoi, 2012) possam estimular diversos mecanismos morfofisiológicos favoráveis à adaptação inicial de essências florestais em campo, informações sobre os benefícios de tais interações em espécies do gênero
Anadenanthera, estabelecidas nas condições regionais, são quase inexistentes (Soares et al., 2017b). Com base nestas demandas, este trabalho teve o objetivo de avaliar o estabelecimento de Anadenanthera colubrina sob inoculação micorrízica e fertilização no Pantanal da Nhecolândia, Mato Grosso do Sul.

\section{Material e métodos}

A área experimental está localizada na Fazenda Santo Expedito, na sub-região da Nhecolândia, Pantanal sul-mato-grossense (1906'20,9''S; 56 44'34,4 W), em fitofisionomias denominadas "cordilheiras", que consistem em antigos diques marginais vegetados, originados da deposição aluvial dos antigos rios (Mercante et al., 2011). Na área selecionada ocorreu a supressão quase total da vegetação arbórea para a atividade pecuária, permanecendo poucas árvores adultas remanescentes. A região possui clima tropical, megatérmico, com temperatura média anual de $25,5^{\circ} \mathrm{C}$, e máximas absolutas ultrapassando os $40^{\circ} \mathrm{C}$. Apresenta longa estação com déficit hídrico, causado pela combinação de um período prolongado sem chuvas, entre abril e outubro, com elevada evapotranspiração potencial (Soriano et al., 1997).

O solo da área foi classificado como Neossolo Quartzarênico hidromórfico plíntico A moderado anêutrico ácido e relevo plano. As características físicas e químicas do solo (valores médios) estão apresentadas na Tabela 1. A seleção de Anadenanthera colubrina var. cebil para o plantio considerou os critérios apresentados por De Sousa et al. (2007), dentre eles a ocorrência e uso da madeira na região, a disponibilidade de sementes, a rusticidade, o conhecimento silvicultural em viveiro e o êxito silvicultural em outros plantios.

Em julho de 2013, frutos de A. colubrina var. cebil foram coletados de matrizes estabelecidas em região denominada "Borda Oeste do Pantanal", no entorno das cidades de Corumbá e Ladário, MS. As sementes foram retiradas das vagens manualmente, fumigadas com gás toxin e armazenadas a $17^{\circ} \mathrm{C}$ até o início do processo de produção das mudas. A semeadura ocorreu em março de 2014, no viveiro de essências florestais situado na Fazenda Nhumirim - Embrapa Pantanal, sub-região da Nhecolândia (18 59'11'S e 56 37'19'W). Nesta etapa, foram semeadas duas sementes por tubete. Quando as plântulas apresentaram dois pares de folhas definitivas, 
foi realizado desbaste, deixando uma plântula por tubete (Soares et al., 2017b).

Tabela 1. Caracterização física e química do solo em cordilheira desmatada no Pantanal da Nhecolândia, Mato Grosso do $\mathrm{Sul}^{1}$.

Table 1. Physical and chemical characterization of soil in a deforested area ("cordilheira" environment) in the Pantanal of Nhecolândia, Mato Grosso do Sul State, Brazil.

\begin{tabular}{|c|c|c|}
\hline \multirow{2}{*}{ Parâmetros ${ }^{1}$} & \multicolumn{2}{|c|}{ Profundidade (cm) } \\
\hline & $0-20$ & $30-45 / 50$ \\
\hline Argila $\left(\mathrm{g} \mathrm{kg}^{-1}\right)$ & 42,0 & 34,0 \\
\hline Areia Total $\left(\mathrm{g} \mathrm{kg}^{-1}\right)$ & 895,0 & 916,0 \\
\hline $\mathrm{pH} \mathrm{CaCl}{ }_{2}$ & 4,0 & 4,2 \\
\hline $\mathrm{Al}^{+3}\left(\mathrm{cmol}_{\mathrm{c}} \mathrm{dm}^{-3}\right)$ & 0,4 & 0,3 \\
\hline $\mathrm{H}^{+}+\mathrm{Al}^{+3}\left(\mathrm{cmol}_{\mathrm{c}} \mathrm{dm}^{-3}\right)$ & 2,6 & 2,2 \\
\hline $\mathrm{Ca}^{+2}\left(\mathrm{cmol}_{\mathrm{c}} \mathrm{dm}^{-3}\right)$ & 0,3 & 0,4 \\
\hline $\mathrm{Mg}^{+2}\left(\mathrm{cmol}_{\mathrm{c}} \mathrm{dm}^{-3}\right)$ & 0,1 & 0,0 \\
\hline $\mathrm{K}^{+}\left(\mathrm{cmol}_{\mathrm{c}} \mathrm{dm}^{-3}\right)$ & 0,1 & 0,0 \\
\hline $\mathrm{Na}^{+}\left(\mathrm{cmol}_{\mathrm{c}} \mathrm{dm}^{-3}\right)$ & 0,0 & 0,0 \\
\hline $\mathrm{SB}\left(\mathrm{cmol}_{\mathrm{c}} \mathrm{dm}^{-3}\right)$ & 0,5 & 0,4 \\
\hline $\mathrm{CTC}_{\mathrm{T}}\left(\mathrm{cmol}_{\mathrm{c}} \mathrm{dm}^{-3}\right)$ & 3,1 & 2,7 \\
\hline $\mathrm{CTC}_{\mathrm{ef}}\left(\mathrm{cmol}_{\mathrm{c}} \mathrm{dm}^{-3}\right)$ & 0,8 & 0,7 \\
\hline $\mathrm{P}\left(\mathrm{mg} \mathrm{dm}^{-3}\right)$ & 17,7 & 12,8 \\
\hline $\mathrm{C}\left(\mathrm{mg} \mathrm{dm}^{-3}\right)$ & 5,4 & 7,5 \\
\hline V $(\%)$ & 14,9 & 15,9 \\
\hline m (\%) & 45,5 & 45,1 \\
\hline
\end{tabular}

${ }^{1} \mathrm{SB}, \mathrm{CTC}_{\mathrm{T}}, \mathrm{CTC}_{\mathrm{e},}, \mathrm{V}$ e m correspondem, respectivamente, à soma de bases, capacidade de troca catiônica total e efetiva, e saturação por bases e por alumínio.

Entre 26 e 28 de maio de 2014 foram selecionadas do viveiro 1.404 mudas para a composição do povoamento em campo. Esta quantia foi submetida à inoculação com uma suspensão contendo água não clorada e inóculo de rizóbios das estirpes BR 4802, BR 9002 e BR 9003, provenientes da Embrapa Agrobiologia (Seropédica, Rio de Janeiro), previamente selecionadas para uso em leguminosas arbóreas (Faria \& Uchôas, 2007; Oliveira Júnior et al., 2010). O lote de mudas foi então dividido para a composição de dois tratamentos principais, sendo uma das metades submetida à inoculação micorrízica (tratamento "plantas inoculadas"). O inóculo empregado consistiu na suspensão, em água não clorada, de uma mistura composta por solo mais raízes colonizadas e esporos de Rhizophagus clarus (sinonímia Glomus clarum, 100 esporos por grama de inóculo) e Gigaspora margarita (30 esporos por grama de inóculo), visando o fornecimento de aproximadamente 40 e 10 esporos de cada espécie por muda, respectivamente. A outra metade das mudas foi mantida sem inoculação micorrízica (tratamento controle). Uma avaliação da colonização micorrízica foi realizada em amostras obtidas em março de 2015, sendo seus percentuais (acima de 84\%), sua intensidade e morfologia reportados em Soares et al. (2017b).

Aárea total do experimento compreendeu 0,53 ha, com 36 árvores em cada subparcela $\left(216 \mathrm{~m}^{2}\right)$, distribuídas em 6 linhas de plantio com 6 árvores cada, no espaçamento $3 \mathrm{~m} \times 2 \mathrm{~m}$ e bordadura simples. Foi utilizado em campo o delineamento experimental em blocos ao acaso com parcelas subdivididas e três repetições. A adoção de blocos teve como finalidade reduzir os efeitos ambientais de possíveis variações locais da profundidade média do lençol freático, ocupando o terço inferior ("TI" - Bloco 1), médio ("TM" - Bloco 2) e superior ("TS" - Bloco 3) do relevo. Em cada bloco foram instalados os dois tratamentos principais (plantas inoculadas com fungos micorrízicos e as plantas do tratamento controle). Cada parcela foi subdividida em quatro tratamentos secundários (subparcelas), correspondentes à aplicação parcelada de doses de nitrogênio e potássio, via fertilização mineral, para o estabelecimento das plantas na área. O emprego de parcelas monoespecíficas visou o estudo da espécie em igualdade de vizinhança, conforme apresentado em De Sousa et al. (2007).

O preparo da área e plantio de $A$. colubrina var. cebil foi realizado em março de 2015, e consistiu na retirada de galhos grossos com auxílio de motosserra e caminhonete, capina mecânica do extrato herbáceo-arbustivo com uso de roçadeira acoplada a trator e roçadeira costal e demarcação das parcelas. As covas foram abertas com motocovadeira até $40 \mathrm{~cm}$ de profundidade, sendo uma pequena parcela do subsolo devolvida ao solo. Em todas as covas, a camada superficial do solo $(0-30 \mathrm{~cm})$ foi misturada mecanicamente a $2 \mathrm{~kg}$ de composto orgânico da marca Organoeste ${ }, 100 \mathrm{~g}$ de calcário dolomítico PRNT $100 \%, 100 \mathrm{~g}$ de superfostato simples $\left(18 \% \mathrm{P}_{2} \mathrm{O}_{5}\right) \mathrm{e}$ $1 \mathrm{~L}$ de hidrogel $\left(3 \mathrm{~g} \mathrm{~L}^{-1}\right)$. O composto orgânico apresentou a seguinte composição (teores totais, base seca $60-65^{\circ} \mathrm{C}$ ): $\mathrm{pH}=7,5, \mathrm{~N}=18,3 \mathrm{~g} \mathrm{~kg}^{-1}, \mathrm{P}_{2} \mathrm{O}_{5}=17,8 \mathrm{~g} \mathrm{~kg}^{-1}, \mathrm{~K}_{2} \mathrm{O}=$ $2,9 \mathrm{~g} \mathrm{~kg}^{-1}, \mathrm{Ca}=83,8 \mathrm{~g} \mathrm{~kg}^{-1}, \mathrm{Mg}=4,3 \mathrm{~g} \mathrm{~kg}^{-1}, \mathrm{~S}=4,3 \mathrm{~g} \mathrm{~kg}^{-1}$, $\mathrm{Cu}=109 \mathrm{mg} \mathrm{kg}^{-1}, \mathrm{Mn}=999 \mathrm{mg} \mathrm{kg}^{-1}, \mathrm{Zn}=202 \mathrm{mg} \mathrm{kg}^{-1}$, $\mathrm{B}=13 \mathrm{mg} \mathrm{kg}^{-1}, \mathrm{Na}=1,98 \mathrm{~g} \mathrm{~kg}^{-1}$, Relação $\mathrm{C}: \mathrm{N}=11: 1$. 
As doses de nutrientes inicialmente estabelecidas para a fertilização dos tratamentos secundários $\left(\mathrm{N}: \mathrm{K}_{2} \mathrm{O}\right.$, g planta $\left.^{-1}\right)$ foram: $\mathrm{NK}_{1}=10: 10(1 \mathrm{x}), \mathrm{NK}_{2}=$ 20:20 (2x), $\mathrm{NK}_{3}=40: 40(4 \mathrm{x}), \mathrm{NK}_{4}=60: 60(6 \mathrm{x})$, sendo a menor dose de nitrogênio e potássio correspondente ao valor mínimo recomendado para o estabelecimento de reflorestamentos mistos com espécies nativas (Gonçalves et al., 2008). O parcelamento da adubação, inicialmente proposto, visava o estabelecimento das plantas ao longo de dois anos após o plantio. Todavia, optou-se pela interrupção após a aplicação da segunda parcela, devido à elevada mortalidade em campo. As doses dos fertilizantes minerais sulfato de amônio (21\% $\mathrm{N})$ e cloreto de potássio $\left(60 \% \mathrm{~K}_{2} \mathrm{O}\right)$ aplicadas estão discriminadas na Tabela 2. Aos dois, quatorze e vinte e três meses após o plantio, foi realizada a contagem de mudas sobreviventes, distinguindo-se, no primeiro período de avaliação, em toda a parcela, o percentual total de plantas sobreviventes e o percentual de plantas em processo de rebrota. Para ao cálculo deste último, foi considerada a razão entre o número total de plantas sobreviventes e o número de plantas com formação de novos brotos após perda total de folíolos por estresse pós transplantio, multiplicado por 100 (procedimento adaptado de Varela et al., 2017). Aos quatorze e aos vinte e três meses foram avaliados, além do percentual total de plantas sobreviventes, a altura $(\mathrm{A}, \mathrm{em} \mathrm{cm})$, o diâmetro do colo (DC, em mm) e a razão entre A:DC (valores médios, $\mathrm{cm} \mathrm{mm}^{-1}$ ) das plantas úteis de cada supbarcela.

A influência do sombreamento resultante da presença de indivíduos arbóreos remanescentes foi mensurada aos vinte e três meses após o plantio, a partir da obtenção do índice de abertura do dossel, procedimento adaptado de Monte et al. (2007). Para tanto, foi obtida uma fotografia digital colorida por subparcela, na entrelinha entre a $3^{\mathrm{a}}$. e $4^{\mathrm{a}}$. linhas de plantio na sua posição central, a $1,5 \mathrm{~m}$ do solo, com câmera fotográfica digital Canon EOS 6D Full Frame acoplada à um lente olho de peixe, ajustada a $8 \mathrm{~mm}$ e dimensões de $3648 \times 2432$ pixel (8,9 megapixel), no modo automático, com a lente apontada para o céu. Um tripé, nível de bolha e bússola foram utilizados para suporte e orientação ao Norte magnético no interior das parcelas. O índice de abertura do dossel foi obtido com o auxílio do software Gap Light Analyser versão 2.0.

Para todas as variáveis, foi realizada a análise de variância seguindo-se o modelo de blocos ao acaso e considerando-se os efeitos de bloco (posição das plantas no relevo), da inoculação com fungos micorrízicos, da aplicação das diferentes doses de fertilizantes nitrogenado e potássico e suas interações, salientando que durante as avaliações o tratamento $\mathrm{NK}_{1}$ foi idêntico ao $\mathrm{NK}_{2}$. A variável em que não se verificou efeito significativo pelo teste $\mathrm{F}$ foi posteriormente excluída para aumento do grau de liberdade do modelo estatístico. Os fatores com efeito significativo pelo teste $\mathrm{F}$ foram submetidos à comparação das médias pelo teste de Tukey. Correlações entre a variação da luz interceptada pelas copas de árvores remanescentes (abertura do dossel), a sobrevivência e as variáveis morfológicas foram verificadas pelo coeficiente de correlação de Pearson, cuja significância foi testada para todos os casos. Para as correlações significativas foram também gerados modelos polinomiais, com distinção da sobrevivência em diferentes posições de relevo e de manejo (inoculação e a adubação). Nesta etapa, o agrupamento da sobrevivência em $\mathrm{NK}_{1}+\mathrm{NK}_{2}$ e $\mathrm{NK}_{3}$ $+\mathrm{NK}_{4}$ visou a distinção das parcelas sob menores e maiores doses de adubos, considerando-se os resultados obtidos pelo teste de médias, obtendo-se assim equações a partir de um maior número de observações.

Tabela 2. Doses de sulfato de amônio $(\mathrm{SA}, 21 \% \mathrm{~N})$ e cloreto de potássio $\left(60 \% \mathrm{~K}_{2} \mathrm{O}\right)$ utilizadas.

Table 2. Ammonium sulfate (SA, $21 \% \mathrm{~N})$ and potassium chloride $\left(60 \% \mathrm{~K}_{2} \mathrm{O}\right)$ doses used.

\begin{tabular}{|c|c|c|c|c|c|c|}
\hline \multirow{3}{*}{ Tratamentos } & \multicolumn{6}{|c|}{ Doses de fertilizantes minerais (g planta ${ }^{-1}$ ) } \\
\hline & \multicolumn{2}{|c|}{$\begin{array}{c}\text { Plantio } \\
\text { (março 2015) }\end{array}$} & \multicolumn{2}{|c|}{$\begin{array}{c}\text { Cobertura } \\
\text { (janeiro 2016) }\end{array}$} & \multicolumn{2}{|c|}{$\begin{array}{c}\text { Total } \\
\text { (plantio + cobertura) }\end{array}$} \\
\hline & SA & KCl & SA & $\mathrm{KCl}$ & $\mathbf{S A}$ & $\mathrm{KCl}$ \\
\hline NK1 & 15 & 5 & 16 & 6 & 31 & 11 \\
\hline $\mathrm{NK} 2$ & 15 & 5 & 16 & 6 & 31 & 11 \\
\hline NK3 & 30 & 10 & 32 & 12 & 62 & 22 \\
\hline NK4 & 30 & 15 & 48 & 15 & 78 & 30 \\
\hline
\end{tabular}




\section{Resultados}

Os efeitos dos fatores ambientais, da inoculação e da adubação sobre a sobrevivência de Anadenanthera colubrina var. cebil em campo entre 2 e 23 meses de idade são apresentados nas Figuras 1 e 2 e nas Tabelas 3 e 4. Pelo teste de Tukey $(\mathrm{p}<0,10)$, aos 2 meses de idade, o percentual total de plantas sobreviventes foi significativamente maior no terço inferior do ambiente de cordilheira ("TI" com 79\%, Figura 1A), e sob a aplicação das doses NK1 e NK2, em relação à NK4 (77\%,
$72 \%$ e $53 \%$ em NK1, NK2 e NK4, respectivamente, Figura $1 \mathrm{G})$. No TI do relevo, comparativamente ao terço superior (TS, Figura 1A), foi observado menor percentual de mudas que, embora sobreviventes, perderam folíolos e estavam em processo de rebrota (38\% e $62 \%$, respectivamente). A inoculação com Rhizophagus clarus e Gigaspora margarita (Figura 1D), bem como a variação da luz interceptada pelas copas de árvores remanescentes (abertura do dossel, Tabela 3) não interferiram na sobrevivência da espécie nesta idade.

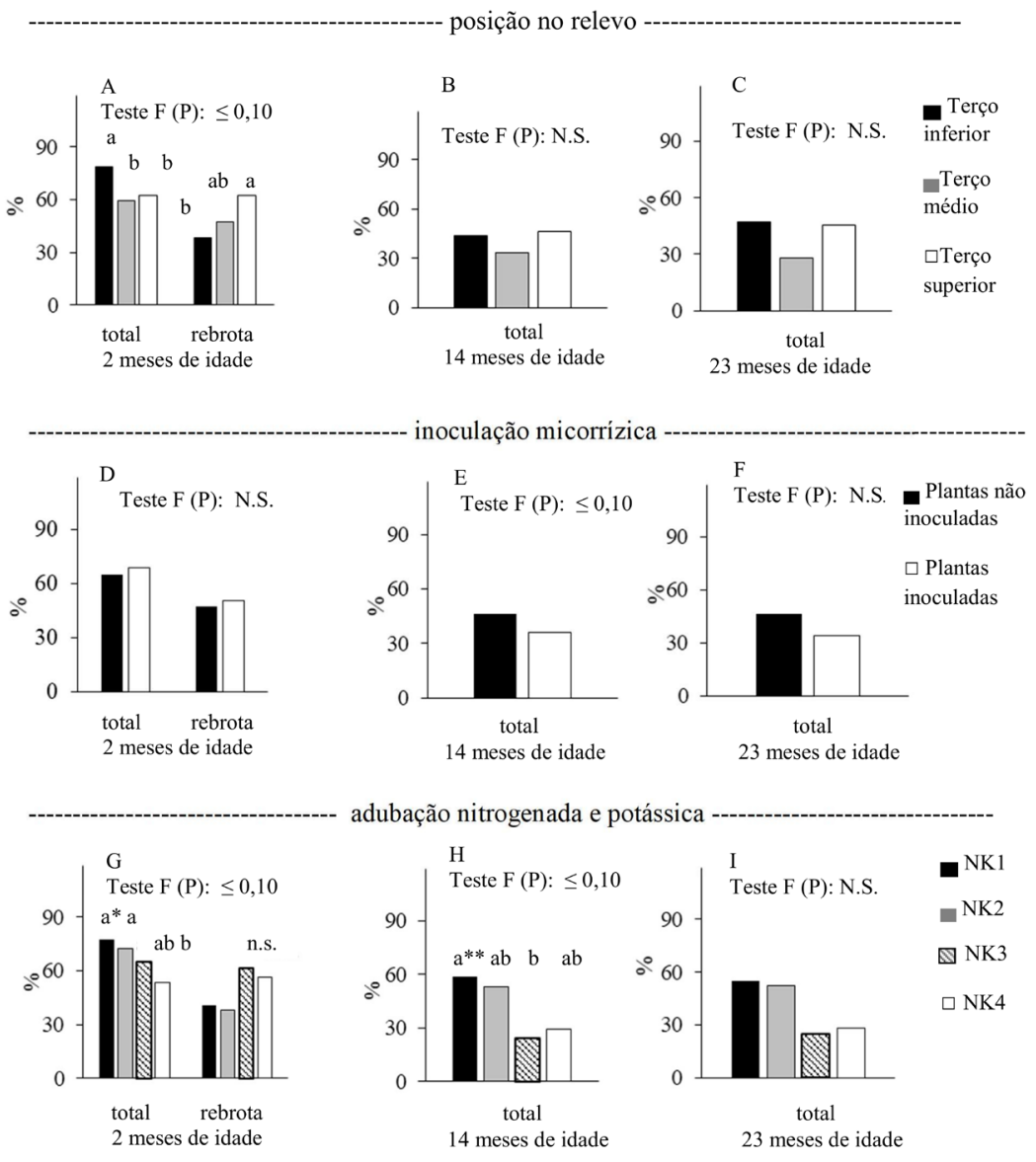

Figura 1. Percentual de Anadenanthera colubrina var. cebil sobrevivente (total) e em processo de rebrota, estabelecida em ambiente de cordilheira no Pantanal da Nhecolândia, MS. Sendo A, B e C: posição das plantas no relevo (terço inferior, médio e superior); D, E e F: plantas não inoculadas e inoculadas com Rhizophagus clarus e Gigaspora margarita; G, H e I: diferentes doses de adubo nitrogenado e potássico (NK1 a NK4). Idades avaliadas: A, D e F: 2 meses; B, E e G: 14 meses; C, F, I: 23 meses. Letras minúsculas iguais, no mesmo período de avaliação, não diferem pelo teste de Tukey (p > 0,1). N. S. e n.s.: não significativo a $10 \%$ de probabilidade (teste $\mathrm{F}$ e de Tukey, respectivamente)

Figure 1. Percentage of Anadenanthera colubrina var. cebil surviving (total) and in the process of regrowth, established in a "cordilheira" environment, in the Pantanal of Nhecolândia, Mato Grosso do Sul State, Brazil. A, B and C: position of the plants in the relief (lower, middle and upper third); D, E and F: plants not inoculated and inoculated with Rhizophagus clarus and Gigaspora margarita; G, H and I: different doses of nitrogen and potassium fertilizers (NK1 to NK4). Ages evaluated in A, D and F: 2 months; B, E and G: 14 months; C, F, I: 23 months. Same lower case letters, in the same evaluation period, do not differ by the Tukey test $(\mathrm{p}>0.1)$. N. S. and n.s. = not significant at $10 \%$ probability (F and Tukey tests, respectively). 
Tabela 3. Efeito da abertura do dossel no percentual total de Anadenanthera colubrina var. cebil sobrevivente, estabelecida em ambiente de cordilheira no Pantanal da Nhecolândia, MS, aos 2, 14 e 23 meses de idade, considerando a posição no relevo, a inoculação micorrízica e a fertilização nitrogenada e potássica.

Table 3. Effect of canopy opening of the remaining trees on the total percentage of Anadenanthera colubrina var. cebil survivor, at 2, 14 and 23 months of age, considering the position in the relief, mycorrhizal inoculation and nitrogen and potassium fertilization. Stand established in a "cordilheira" environment, in the Pantanal of Nhecolândia, Mato Grosso do Sul State, Brazil.

\begin{tabular}{|c|c|c|c|c|c|}
\hline Variáveis & & Idade (meses) & Equação de regressão & $\mathbf{R}^{2}$ & p-value \\
\hline \multirow{9}{*}{ Posição no relevo } & \multirow{3}{*}{ Terço inferior } & 2 & - & - & n.s. \\
\hline & & 14 & $-0,0795 \times 2+9,6958 x-216,32$ & 0,81 & $*$ \\
\hline & & 23 & $-0,0779 x^{2}+9,2644 x-190,19$ & 0,87 & $*$ \\
\hline & \multirow{3}{*}{ Terço médio } & 2 & - & - & n.s. \\
\hline & & 14 & $0,1327 \times 2-24,633 x+1166,6$ & 0,80 & $*$ \\
\hline & & 23 & - & - & n.s. \\
\hline & \multirow{3}{*}{ Terço superior } & 2 & - & - & n.s. \\
\hline & & 14 & $-0,0513 \times 2+4,7126 x-21,449$ & 0,71 & $*$ \\
\hline & & 23 & - & & n.s. \\
\hline \multirow{6}{*}{$\begin{array}{l}\text { Inoculação } \\
\text { micorrízica }\end{array}$} & \multirow{3}{*}{$\begin{array}{l}\text { Plantas não } \\
\text { inoculadas }\end{array}$} & 2 & - & - & n.s. \\
\hline & & 14 & $-0,0251 x^{2}+2,4139 x+10,902$ & 0,61 & $*$ \\
\hline & & 23 & $-0,0319 x^{2}+3,0923 x-0,4155$ & 0,71 & $*$ \\
\hline & \multirow{3}{*}{ Plantas Inoculadas } & 2 & - & - & n.s. \\
\hline & & 14 & $-0,0362 x^{2}+2,8471 x+44,426$ & 0,73 & \\
\hline & & 23 & $-0,0316 x^{2}+2,3777 x+49,541$ & 0,66 & $*$ \\
\hline \multirow{6}{*}{$\begin{array}{c}\text { Adubação } \\
\text { nitrogenada e } \\
\text { potássica }\end{array}$} & \multirow{3}{*}{$\mathrm{NK} 1+\mathrm{NK} 2$} & 2 & - & - & n.s. \\
\hline & & 14 & $-0,0431 x^{2}+4,4113 x-22,95$ & 0,80 & $*$ \\
\hline & & 23 & $-0,0384 x^{2}+3,8594 x-10,992$ & 0,77 & $*$ \\
\hline & \multirow{3}{*}{$\mathrm{NK} 3+\mathrm{NK} 4$} & 2 & - & - & n.s. \\
\hline & & 14 & $-0,0272 x^{2}+2,5375 x+0,1965$ & 0,71 & $*$ \\
\hline & & 23 & $-0,0266 x^{2}+2,096 x+30,438$ & 0,75 & $*$ \\
\hline
\end{tabular}

* = significativo a 5\% de probabilidade; n.s. = não significativo; $\mathrm{R}^{2}=$ coeficiente de determinação.

Tabela 4. Matriz de correlação de Pearson entre as variáveis: sobrevivência total, altura total, diâmetro do colo, razão entre altura e diâmetro do colo (A:DC) de Anadenanthera colubrina var. cebil e abertura do dossel de árvores remanescentes aos 14 e 23 meses de idade. Plantio estabelecido em ambiente de cordilheira no Pantanal da Nhecolândia, MS.

Table 4. Pearson's correlation matrix between the total survival, total height, neck diameter, ratio between height and neck diameter (A: DC) of Anadenanthera colubrina var. cebil and the canopy opening of the remaining trees at 14 and 23 months of age. Stand established in a "cordilheira" environment, in the Pantanal of Nhecolândia, Mato Grosso do Sul State, Brazil.

\begin{tabular}{|c|c|c|c|c|c|}
\hline & $\begin{array}{c}\text { Abertura do dossel } \\
(\%)\end{array}$ & $\begin{array}{c}\text { Sobreviventes total } \\
(\%)\end{array}$ & $\begin{array}{l}\text { Altura } \\
\text { (m) }\end{array}$ & $\begin{array}{l}\text { Diâmetro do colo } \\
(\mathrm{mm})\end{array}$ & $\begin{array}{c}\text { Razão A:DC } \\
\text { (cm:mm) }\end{array}$ \\
\hline & & 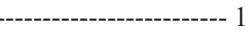 & de idade & ---------------------- & \\
\hline Abertura do dossel & 1 & & & & \\
\hline Sobreviventes total & $-0,72^{*}$ & 1 & & & \\
\hline Altura & $-0,19^{\text {n.s. }}$ & $0,08^{\text {n.s. }}$ & 1 & & \\
\hline Diâmetro do colo & $-0,10^{\text {n.s. }}$ & $0,06^{\text {n.s. }}$ & $0,92^{*}$ & 1 & \\
\hline \multirow[t]{2}{*}{ Razão A:DC } & $-0,28^{\text {n.s. }}$ & $0,08^{\text {n.s. }}$ & $0,69^{*}$ & $0,39^{*}$ & 1 \\
\hline & & 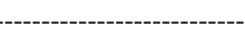 & s de idad & ------------- & \\
\hline Abertura do dossel & 1 & & & & \\
\hline Sobreviventes total & $-0,77^{*}$ & 1 & & & \\
\hline Altura & $-0,25^{\text {n.s. }}$ & $0,01^{\text {n.s. }}$ & 1 & & \\
\hline Diâmetro do colo & $-0,16^{\text {n.s. }}$ & $0,05^{\text {n.s. }}$ & $0,91^{*}$ & 1 & \\
\hline Razão A:DC & $-0,44^{*}$ & $0,25^{\text {n.s. }}$ & $0,75^{*}$ & $0,49^{*}$ & 1 \\
\hline
\end{tabular}

*correlação significativa a $10 \%$ de probabilidade; n.s.: não significativo. 

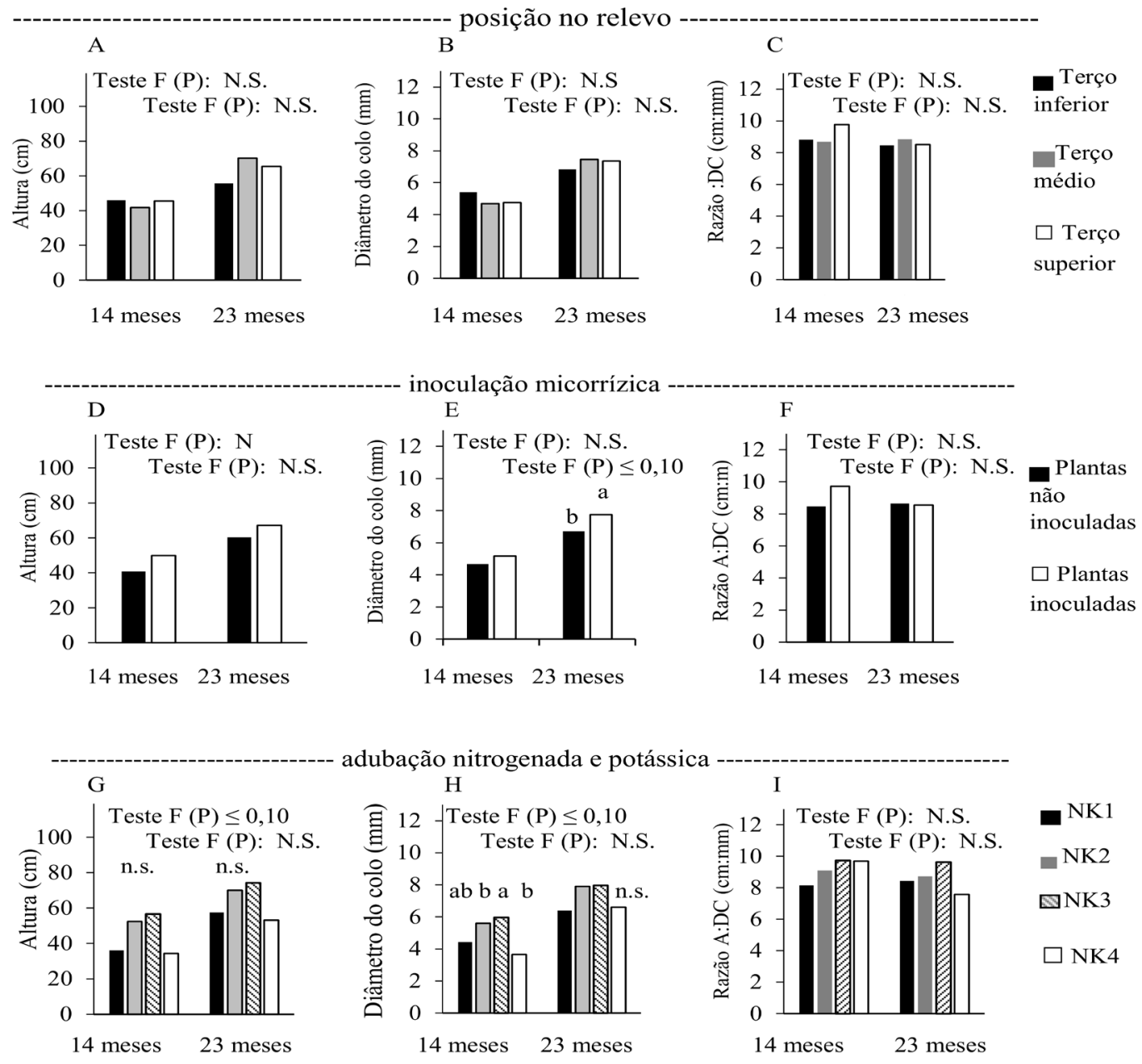

Figura 2. Efeito da posição das plantas no relevo (A, B e C), da inoculação (D, E e F) e da fertilização nitrogenada e potássica (NK, em G, H e I) no desenvolvimento em altura (A, D e G), no diâmetro do colo (B, E e H) na razão altura: diâmetro do colo (A:DC, em C, F e I) de Anadenanthera colubrina var. cebil estabelecida em ambiente de cordilheira no Pantanal da Nhecolândia, MS, aos 2, 14 e 23 meses de idade. Sendo: A, B e C: posição das plantas no relevo (terço inferior, médio e superior); D, E e F: plantas não inoculadas e inoculadas com Rhizophagus clarus e Gigaspora margarita; G, H e I: diferentes doses de adubo nitrogenado e potássico (NK1 a NK4). Letras minúsculas iguais, no mesmo período de avaliação, não diferem pelo teste de Tukey $(\mathrm{p}>0,1)$. N.S. e n.s. = não significativo a $10 \%$ de probabilidade pelo teste $\mathrm{F}$ e de Tukey, respectivamente.

Figure 2. Effect of plant position on relief (A, B and C), inoculation (D, E and F) and different doses of nitrogen plus potassium fertilizers (NK, G, H and I) on height ( $\mathrm{A}, \mathrm{D}$ and $\mathrm{G})$, in the neck diameter $(\mathrm{B}, \mathrm{E}$ and $\mathrm{H})$ in the height: neck diameter ratio (A: DC, in C, F and I) of A. colubrina var. cebil, at 2, 14 and 23 months of age. Stand established in a "cordilheira" environment, in the Pantanal of Nhecolândia, Mato Grosso do Sul State, Brazil. A, B and C: position of the plants in the relief (lower, middle and upper third); D, E and F: not inoculated and inoculated plants with Rhizophagus clarus and Gigaspora margarita; G, H and I: doses of nitrogen plus potassium fertilizer (NK1 to NK4). Same lower case letters, in the same evaluation period, do not differ by the Tukey test $(\mathrm{p}>0.1)$. N.S. and n.s. = not significant at $10 \%$ probability by the F and Tukey tests, respectively. 
Aos 14 meses, a inoculação (Figura 1E), a adubação (Figura $1 \mathrm{H}$ ) e a interação entre a posição no relevo e a inoculação promoveram alterações no percentual de plantas sobreviventes, não havendo, todavia, interação entre inoculação e adubação $(\mathrm{p}<0,10)$. Neste período, foi observada diferença significativa entre os tratamentos NK1 e NK3 ( $p<0,10$, Figura 1H). Estes efeitos não foram mantidos aos 23 meses de idade, conforme pode ser observado nas Figuras 1F e 1I. As correlações entre sobrevivência e abertura do dossel (Tabela 4), por outro lado, foram significativas nestas duas idades $(-0,72$ e $-0,77$ aos 14 e aos 23 meses de idade, respectivamente, $\mathrm{p}<0,10$ ). Foi possível estabelecer modelos polinomiais de segundo grau, considerando-se os fatores ambientais e de manejo avaliados, conforme apresentado na Tabela 3. Aos 23 meses de idade verificou-se que, sob abertura do dossel superior a $51 \%$, o TI do relevo apresentou condições mais favoráveis de sobrevivência da espécie, em relação ao TS. Quanto à adubação, estima-se que aos 23 meses de idade, a espécie apresenta potencial de sobrevivência em campo igual ou superior a $75 \%$ $(\mathrm{p}<0,05)$, todavia com o uso de menores doses de adubação nitrogenada e potássica, associado à abertura de dossel entre $33 \%$ e $66 \%$.

O crescimento da espécie em campo (Figura 2), em todas as condições ambientais e de manejo, foi lento durante o período de avaliação. Não houve efeito isolado da posição das plantas no relevo sobre a altura (Figura 2A), o diâmetro do colo (Figura $2 \mathrm{~B}$ ) e a razão altura: diâmetro do colo (Figura 2C) aos 14 e 23 meses de idade. A inoculação micorrízica resultou em plantas com maior DC somente aos 23 meses de idade (Figura 2E, $\mathrm{p} \leq 0,10$ ), época em que razão A:DC foi inversamente relacionada à variação da luz interceptada pelas copas de árvores remanescentes (Tabela 4, p < 0,10). Quanto à adubação, diferentes doses de fertilizantes nitrogenado e potássico resultaram em alterações no crescimento em altura e no diâmetro do colo aos 14 meses de idade $(p \leq 0,10$, Figuras $2 \mathrm{G}$ e $2 \mathrm{H})$.

\section{Discussão}

$\mathrm{O}$ estabelecimento das mudas de Anadenanthera colubrina var. cebil, procedentes de matrizes do Bioma Pantanal, em todos os contextos avaliados, foi caracterizado pelo lento arranque inicial das mudas em campo (Figuras 2A a 2I). Este comportamento pode estar relacionado à estratégia fisiológica de sobrevivência da espécie em ambientes com escassez de nutrientes e água, a partir da diminuição da atividade fotossintética e da taxa de renovação de tecidos das plantas (Markesteijn et al., 2011). A presença de sistema radicular tuberoso e a perda parcial ou total de folíolos são também descritos por Da Silva \& Barbosa (2000) como mecanismos de tolerância à seca das espécies desse gênero, sendo uma condição intrínseca ao ritmo de crescimento de essências florestais típicas de regiões que apresentam sazonalidade climática (Mattos et al., 1999).

Analogamente, a maior sobrevivência inicial de mudas no terço inferior do ambiente de cordilheira (Figura 1A) pode estar relacionada à adjacência desta porção do terreno a um corpo hídrico superficial (baía), o que resultaria em aumento da oferta de água do lençol freático às camadas superficiais do solo (Alkhaier et al., 2012; Pirastru \& Niedda, 2013). A diminuição da sobrevivência aos 14 e 23 meses de idade e sob maior abertura do dossel (Tabelas 3 e 4) também indica uma resistência limitada da procedência à radiação solar nos estágios iniciais de desenvolvimento. Ferreira et al. (2012) observaram que plântulas de A. colubrina var. cebil procedente da Caatinga, quando expostas a pleno sol, tendem a apresentar diminuição dos teores de clorofila total em relação a indivíduos sob sombreamento. A intensificação da degradação deste pigmento pode resultar em danos ao aparato fotossintético, culminando em comprometimento de importantes processos vitais às plantas (Roeber et al., 2021). A preferência de A. colubrina var. cebil por níveis intermediários de sombra para seu desenvolvimento inicial corrobora com Ferreira et al. (2012), que classificam a espécie como umbrófila nas primeiras fases de vida. No entanto, essa classificação não é consensual, conforme se verifica em Carvalho (2003), que a considera essencialmente heliófila.

Os poucos dados disponíveis sobre inoculação micorrízica de A. colubrina var. cebil, procedente do Bioma Pantanal indicam que a técnica promove aumento da colonização micorrízica, todavia sem benefícios para a qualidade silvicultural de mudas em viveiro (Soares et al., 2017b). No presente estudo, a despeito do incremento de $16 \%$ no diâmetro do colo aos 23 meses de idade (Figura 2E), as plantas inoculadas apresentaram percentual de sobrevivência da espécie similar (Figuras $1 \mathrm{D}$ e $1 \mathrm{~F}$ ) ou inferior (Figura 1E) às sem inoculação. Os resultados diferem dos observados por Vandresen et al. (2007), que registraram maior sobrevivência de 
A. colubrina produzidas com inoculação micorrízica e sem fertilização química, em plantio estabelecido no bioma Mata Atlântica. Neste cenário, estudos recentes apontam como alternativa ao manejo microbiológico de espécies arbóreas a dupla inoculação envolvendo fungos micorrízicos e rizóbios (Marques et al., 2001; Gross et al., 2004; Dias et al., 2012; Cely et al., 2016; Tavares et al., 2016; Bournaud et al., 2018, Freire et al., 2020), não avaliada no presente estudo. Para as duas condições de inoculação, informações adicionais sobre a compatibilidade entre inóculos e hospedeiro (Gross et al., 2004), a competitividade dos materiais selecionados com microorganismos nativos do solo (Chu et al., 2001) e a prospecção de organismos indígenas simbiontes (Santos et al., 2008a; Barea et al., 2011) poderão subsidiar, no futuro, a adequação da inoculação às especificidades de cada contexto em que se aplica a recomposição vegetal (Santos et al., 2008b).

Apesar da importância do suprimento de nitrogênio e potássio para o estabelecimento inicial de algumas espécies florestais (Gonçalves et al., 2008; Freitas et al., 2015), no presente estudo a aplicação de doses iguais ou superiores a $31 \mathrm{~g}$ de sulfato de amônio e de $11 \mathrm{~g}$ de cloreto de potássio por planta nos dois primeiros anos de plantio não favoreceu a sobrevivência da espécie em campo (Figuras $1 \mathrm{G}$ a 1I). Informações sobre o comportamento do gênero Anadenanthera mediante fertilização são ainda escassos e contraditórios, em reflexo à ampla gama de condições estabelecidas nos ensaios experimentais, bem como em razão das diferenças entre materiais genéticos quanto à velocidade de crescimento e comportamento fisiológico em condições distintas de solo, clima e manejo. Chaves et al. (2006) verificaram que a aplicação de sulfato de amônio ou de nitrato de amônio em $A$. macrocarpa inoculada com rizóbio pode retardar o desenvolvimento inicial desta espécie, fato atribuído à possível inibição da simbiose entre bactéria nodulífera e raízes. Respostas positivas do gênero ao uso de fertilizantes de liberação lenta foram, todavia, observados para $A$. colubrina (angico branco) por Lang et al. (2011), A. peregrina por Rossa et al. (2015) e $A$. colubrina por Brondani et al. (2008). Os resultados obtidos apontam para a necessidade de mais estudos voltados ao ajuste do manejo da fertilidade do solo para a espécie nas condições apresentadas. Atenção ao calendário de plantio, à época de adubação, às doses e fontes de nutrientes são fundamentais para se evitar a sujeição das mudas ao efeito salino de adubos e à lixiviação de nutrientes.

\section{Conclusões}

Mudas de Anadenanthera colubrina var. cebil, procedentes do bioma Pantanal, apresentam melhores condições de sobrevivência e desenvolvimento em campo quando plantadas na porção da cordilheira mais próxima a baía, sob maior oferta de água do lençol freático, sombreamento moderado e com a aplicação de $15 \mathrm{~g}$ de sulfato de amônio e de $5 \mathrm{~g}$ de cloreto de potássio por planta, no ato do plantio. A inoculação com Rhizophagus clarus e Gigaspora margarita promoveu incremento no crescimento aos 23 meses de idade, não aumentando a sobrevivência da espécie no ambiente estudado.

Dada a escassez de informações relacionadas à ecologia e silvicultura da procedência avaliada no presente trabalho, recomendam-se estudos complementares voltados ao seu manejo, como a viabilidade de plantios consorciados com espécies sombreadoras e estratégias de incremento da matéria orgânica concomitante ao restabelecimento das funções ecossistêmicas do povoamento, a fim de aumentar a capacidade de restabelecimento da vegetação arbórea em fragmentos desmatados e permitir o uso multifuncional dos sistemas de produção agropecuária do Pantanal.

\section{Agradecimentos}

Aos funcionários do viveiro de mudas do Projeto Biomas na Fazenda Nhumirim, pelo valioso auxílio na condução das atividades de campo. Às pesquisadoras Cátia Urbanetz, Suzana Maria de Salis e a todos os colaboradores da Embrapa Pantanal envolvidos no apoio técnico e logístico ao presente estudo.

Informamos que a pesquisa apresentada é parte componente do Projeto Biomas, executado pela Confederação da Agricultura e Pecuária do Brasil e pela Empresa Brasileira de Pesquisa Agropecuária. São patrocinadores deste projeto a Fundação de Apoio à Pesquisa e ao Desenvolvimento (FAPED), o BNDES, Senar, Sebrae, Monsanto e John Deere.

Pesq. flor. bras., Colombo, v. 41, e202002129, p. 1-12, 2021 


\section{Referências}

Alkhaier, F. et al. Shallow groundwater effect on land surface temperature and surface energy balance under bare soil conditions: modeling and description. Hydrology and Earth System Sciences, v. 16 , n. 7, p. 1817-1831, 2012. https://doi.org/10.5194/hess-161817-2012.

Alves, F. V. \& Karvatte Junior, N. Benefícios da sombra em sistemas em integração lavoura-pecuária-floresta nos trópicos. In: Bungenstab, D. J. et al. (ed.). ILPF: inovação com integração de lavoura, pecuária e floresta. Brasília, DF: Embrapa, 2019. p. 526-541. Disponível em: https://www.alice.cnptia.embrapa.br/bitstream/doc/1112924/1/ Beneficiosdasombraemsistemas.pdf. Acesso em: 10 abr. 2020.

Barea, J. M. et al. Ecological and functional roles of mycorrhizas in semi-arid ecosystems of Southeast Spain. Journal of Arid Environments, v. 75, p. 1292-1301, 2011. https://doi.org/10.1016/j. jaridenv.2011.06.001.

Barreto, H. M. et al. Enhancement of the antibiotic activity of aminoglycosides by extracts from Anadenanthera colubrina (Vell.) Brenan var. cebil against multi-drug resistant bacteria. Natural Product Research, v. 30, n. 11, p. 1289-1292, 2016. https://doi.org /10.1080/14786419.2015.1049177.

Bournaud, C. et al. Interdependency of efficient nodulation and arbuscular mycorrhization in Piptadenia gonoacantha, a Brazilian legume tree. Plant, Cell \& Environment, v. 41, n. 9, p. 2008-2020, 2018. https://doi.org/10.1111/pce.13095.

Brasil. Ministério das Relações Exteriores. Pretendida contribuição nacionalmente determinada para consecução do objetivo da Convenção: Quadro das Nações Unidas sobre Mudanças do Clima. Brasília, DF, 2015. Disponível em: https://www.gov.br/mre/pt-br/ arquivos/documentos/clima/brasil-indc-portugues.pdf. Acesso em: 10 out. 2021.

Brasil. Ministério do Meio Ambiente. Resolução CONABIO nº 6, de 3 de setembro de 2013. Brasília, DF, 2013. Disponível em: https:// www.icmbio.gov.br/portal/images/stories/docs-plano-de-acaoARQUIVO/00-saiba-mais/02_-_RESOLU\%C3\%87\%C3\%83O CONABIO_N\%C2\%BA_06 DE_03 DE_SET DE_ 2013.pdf. Acesso em: 26 mar. 2020.

Brondani, G. E., et al. Fertilização de liberação controlada no crescimento inicial de angico-branco. Scientia Agraria, v. 9, n. 2, p. 167-176, 2008. Disponível em: https://www.redalyc.org/ pdf/995/99516825006.pdf. Acesso em: 24 maio 2021.

Bustamante, M. M. et al. Ecological restoration as a strategy for mitigating and adapting to climate change: lessons and challenges from Brazil. Mitigation and Adaptation Strategies for Global Change, v. 24, p. 1249-1270, 2019. https://doi.org/10.1007/s11027018-9837-5.

Carnevali, N. H. S. et al. Sobrevivência e crescimento inicial de espécies arbóreas nativas implantadas em pastagem degradada. Floresta, v. 46, n. 2, p. 277-286, 2016. http://doi.org/10.5380/ rf.v46i2.42881.

Carvalho, P. E. R. Espécies arbóreas brasileiras. Brasília, DF: Embrapa Informação Tecnológica; Colombo: Embrapa Florestas, 2003. v. 1, 1039 p.
Cely, M. V. et al. Inoculation of Schizolobium parahyba with mycorrhizal fungi and plant growth-promoting rhizobacteria increases wood yield under field conditions. Frontiers in Plant Science, v. 7, n. 1708, 2016. https://doi.org/10.3389/fpls.2016.01708.

Chaves, L. L. B. et al. Crescimento de mudas de Anadenanthera macrocarpa (Benth) Brenan (angico-vermelho) em substrato fertilizado e inoculado com rizóbio. Revista Árvore, v. 30, n. 6, p. 911-919, 2006. https://doi.org/10.1590/S0100-67622006000600006.

Chu, E. Y. et al. Efeitos da inoculação micorrízica em mudas de gravioleira em solo fumigado e não fumigado. Pesquisa Agropecuária Brasileira, v. 36, n. 4, p. 671-680, 2001. https://doi. org/10.1590/S0100-204X2001000400010.

Da Silva, L. M. B. \& Barbosa, D. C. A. Crescimento e sobrevivência de Anadenanthera macrocarpa (Benth.) Brenan (LEGUMINOSAE), em uma área de caatinga, Alagoinha, PE. Acta Botânica Brasilica, v. 14, n. 3, p. 251-261, 2000. https://doi.org/10.1590/S010233062000000300003 .

De Sousa, L. P. et. al. Recuperação ambiental em áreas de estepe do Primeiro Planalto Paranaense, mediante plantio de espécies arbóreas. Pesquisa Florestal Brasileira, v. 55, p. 95, 2007. Disponível em: https://pfb.cnpf.embrapa.br/pfb/index.php/pfb/article/view/117. Acesso em: 3.jun.2021.

Dias, P. C. et al. Micorriza arbuscular e rizóbios no enraizamento e nutrição de mudas de angico-vermelho. Revista Árvore, v. 36, n. 6, p. 1027-1037, 2012. https://doi.org/10.1590/S010067622012000600004.

Faria, S. M. \& Uchôas, E. S. Indicação de estirpes de rizóbio eficientes na fixação biológica de nitrogênio para espécies de uso múltiplo, atualização ano base 2006. Seropédica: Embrapa Agrobiologia, 2007. 16 p. (Embrapa Agrobiologia. Documentos, 228). Disponível em: http:/ainfo.cnptia.embrapa.br/digital/bitstream/ CNPAB-010/34394/1/doc228.pdf. Acesso em: 5 nov. 2015.

Ferreira, W. N. et al. Crescimento inicial de Piptadenia stipulacea (Benth.) Ducke (Mimosaceae) e Anadenanthera colubrina (Vell.) Brenan var. cebil (Griseb.) Altshul (Mimosaceae) sob diferentes níveis de sombreamento. Acta Botanica Brasilica, v. 26, n. 2, p. 408414, 2012. http://dx.doi.org/10.1590/S0102-33062012000200016.

Freire, J. M. et al. Symbiotic efficiency of inoculation with nitrogenfixing bacteria and arbuscular mycorrhizal fungi in Tachigali vulgaris seedlings. Revista Árvore, v. 44, 2020. https://doi.org/10.1590/1806908820200000024.

Freitas, P. C. et al. Efeito da disponibilidade hídrica e da aplicação de potássio e sódio nas características anatômicas do lenho juvenil de Eucalyptus grandis. Revista Árvore, v. 39, n. 2, p. 405-416, 2015. https://doi.org/10.1590/0100-67622015000200020.

Gonçalves, J. L. M. et al. Recuperação de solos degradados. In: Kageyama, P. Y. et al. (org.). Restauração ecológica de ecossistemas naturais. Botucatu, SP: FEPAF, 2008, p. 111-163.

Gross, E. et al. Nodulation and mycorrhizal infection in Anadenanthera peregrina var. falcata on autoclaved and non-autoclaved Cerrado soil. Revista Brasileira de Ciência do Solo, v. 28, n. 1, p. 95-101, 2004. https://doi.org/10.1590/S0100-06832004000100010. 
Isernhagen, I. Listagem florística de espécies arbóreas e arbustivas de Mato Grosso: um ponto de partida para projetos de restauração ecológica. Sinop, MT: Embrapa Agrossilvipastoril, 2015. 166 p. (Embrapa Agrossilvipastoril. Documentos, 4). Disponível em: https:// ainfo.cnptia.embrapa.br/digital/bitstream/item/124616/1/cpamt2015-isernhagen-listagem-floristica-especie-arborea-arbustiva-mt. pdf. Acesso em: 5 jun. 2021.

Kongsager, R. et al. Addressing climate change mitigation and adaptation together: a global assessment of agriculture and forestry projects. Environmental Management, v. 57, n. 2, p. 271-282, 2016. https://doi.org/10.1007/s00267-015-0605-y.

Lang, A. et al. Aplicação de fertilizante de liberação lenta no estabelecimento de mudas de ipê-roxo e angico-branco em área de domínio ciliar. Floresta, v. 41, n. 2, 2011. http://dx.doi.org/10.5380/ rf.v41i2.21874.

Lima, G. D. S., et al. Inventory in situ of plant resources used as fuel in the Semiarid Region of Northeast Brazil. Brazilian journal of Biological Sciences, v. 3, n. 5, p. 45-62, 2016. http://dx.doi. org/10.21472/bjbs.030505.

Locatelli, B. et al. Tropical reforestation and climate change: beyond carbon. Restoration Ecology, v. 23, n. 4, p. 337-343, 2015. https:// doi.org/10.1111/rec.12209.

Machado, M. R. et al. Silvicultural performance of five forest species in the central Brazilian Amazon. Acta Amazonica, v. 48, n. 1, p. 1017, 2018. https://doi.org/10.1590/1809-4392201700602.

Markesteijn, L. et al. Hydraulics and life history of tropical dry forest tree species: coordination of species drought and shade tolerance. New Phytologist, v. 191, n. 2, p. 480-495, 2011. https:// doi.org/10.1111/j.1469-8137.2011.03708.x.

Marques, M. S. et al. Dual inoculation of a woody legume (Centrolobium tomentosum) with rhizobia and mycorrhizal fungi in south-eastern Brazil. Agroforestry Systems, v. 52, p. 107-117, 2001. http://dx.doi.org/10.1023/A:1010637401475.

Martinotto, F. et al. Sobrevivência e crescimento inicial de espécies arbóreas nativas do Cerrado em consórcio com mandioca. Pesquisa Agropecuária Brasileira, v. 47, n. 1, p. 22-29, 2012. https://doi. org/10.1590/S0100-204X2012000100004.

Mattos, P. P de et al. Identification of annual growth rings based on periodical shoot growth. Tree ring analysis. Wallingford: CAB, 1999. v. 1, p. 139-145.

Mercante, M. A. et al. Geomorphology and habitat diversity in the Pantanal. Brazilian Journal of Biology, v. 71, n. 1, p. 233-240, 2011. http://dx.doi.org/10.1590/S1519-69842011000200002.

Metzger, J. P. et al. Por que o Brasil precisa de suas Reservas Legais. Perspectives in Ecology and Conservation, v. 17, n. 3, p. 104-116, 2019. https://doi.org/10.1016/j.pecon.2019.09.001.

Monte, M. A. et al. Métodos indiretos de estimação da cobertura de dossel em povoamentos de clone de eucalipto. Pesquisa Agropecuária Brasileira, v. 42, n. 6, p. 769-775, 2007. https://doi. org/10.1590/S0100-204X2007000600002.

Nascimento, D. F. et al. Crescimento inicial de seis espécies florestais em diferentes espaçamentos. Cerne, v. 18, p. 159-165, 2012. https:// doi.org/10.1590/S0104-77602012000100019.
Oliveira Júnior, J. Q. de et al. Estirpes de rizóbio indicadas para a inoculação de espécies de leguminosas florestais: aproximação 2010. Seropédica: Embrapa Agrobiologia, 2010. 21 p. (Embrapa Agrobiologia. Documentos, 268).

Pessoa, W. S. et al. Effects of angico extract (Anadenanthera colubrina var. cebil) in cutaneous wound healing in rats. Acta Cirurgica Brasileira, v. 27, n. 10, p. 655-670, 2012. https://doi. org/10.1590/S0102-86502012001000001.

Pirastru, M. \& Niedda, M. Evaluation of the soil water balance in an alluvial flood plain with a shallow groundwater table. Hydrological Sciences Journal, v. 58, n. 4, p. 898-911, 2013. https://doi.org/10. 1080/02626667.2013.783216.

Roeber, V. M. et al. Light acts as a stressor and influences abiotic and biotic stress responses in plants. Plant, Cell \& Environment, v. 44, n. 3, 645-664, 2021. https://doi.org/10.1111/pce.13948.

Rossa, Ü. B. et al. Fertilizante de liberação lenta no desenvolvimento de mudas de Anadenanthera peregrina (L.) Speg. (angico-vermelho) e Schinus terebinthifolius Raddi (aroeira-vermelha). Ciência Florestal, v. 25 , n. 4, p. 841-852, 2015. https://doi.org/10.5902/1980509820582.

Salis, S. M. et al. Distribuição e abundância de espécies arbóreas em cerradões no Pantanal, Estado do Mato Grosso do Sul, Brasil. Brazilian Journal of Botany, v. 29, n. 3, p. 339-352, 2006. https:// doi.org/10.1590/S0100-84042006000300002.

Santos, D. R. et al. Micorriza e rizóbio no crescimento e nutrição em N e P de mudas de angico-vermelho. Revista Caatinga, v. 21, n. 1, p. 76-82, 2008a. Disponível em: http://www.redalyc.org/articulo. oa?id=237117576011. Acesso em: 3 jun. 2021.

Santos, J. G. D. et al. Eficiência de fungos micorrízicos arbusculares isolados de solos de áreas de mineração de bauxita no crescimento inicial de espécies nativas. Revista Brasileira de Ciência do Solo, v. 32, n. 141-150, 2008b. https://doi.org/10.1590/S010006832008000100014 .

Scarante, A. et. al. Distribution of Handroanthus heptaphyllus in Brazil and future projections according to global climate change. Revista Geama, v. 3, p. 201-207, 2017. Disponível em: http://ead. codai.ufrpe.br/index.php/geama/article/view/1533. Acesso em: 3 jun. 2021.

Singh, R. K. \& Gogoi, P. Augmented growth of long pepper in response to arbuscular mycorrhizal inoculation. Journal of Forestry Research, v. 23, n. 2, p. 339-344, 2012. https://doi.org/10.1007/ s11676-012-0262-4.

Soares, M. T. S. et al. Flutuação do lençol freático em vegetação arbórea e pastagem introduzida no Pantanal brasileiro: 2010-2014. In: Congresso Brasileiro de Agrometeorologia, 20.; Simpósio de Mudanças Climáticas e Desertificação do Semiárido Brasileiro, 5., 2017, Juazeiro, Petrolina. A agrometeorologia na solução de problemas multiescala: anais. Petrolina: Embrapa Semiárido: Univasf, 2017a.

Soares, M. T. S. et al. Qualidade de mudas de espécies arbóreas procedentes do Bioma Pantanal e inoculadas com fungos micorrízicos. Pesquisa Florestal Brasileira, v. 37, n. 91, p. 311-322, 2017b. https://doi.org/10.4336/2017.pfb.37.91.1424. 
Soldati, G. T. \& de Albuquerque, U. P. Impact assessment of the harvest of a medicinal plant (Anadenanthera colubrina (Vell.) Brenan) by a rural semi-arid community (Pernambuco), northeastern Brazil. International Journal of Biodiversity Science, Ecosystem Services \& Management, v. 6, n. 3-4, p. 106-118, 2010. https://doi. org/10.1080/21513732.2011.565729.

Soriano, B. M. A. et al. (org.). Plano de utilização da Fazenda Nhumirim. Corumbá: EMBRAPA-CPAP, 1997. 72 p. (EMBRAPACPAP. Documentos, 21)

Tavares, S. R. L. et al. Produção de mudas de sabiá Mimosa caesalpiniaefolia Benth noduladas e micorrizadas em diferentes substratos. Holos, v. 7, p. 231-241, 2016. https://doi.org/10.15628/ holos.2016.3933.
Vandresen, J. et al. Inoculação de fungos micorrízicos arbusculares e adubação na formação e pós-transplante de mudas de cinco espécies arbóreas nativas do sul do Brasil. Acta Botanica Brasilica, v. 21, n. 753-765, 2007. https://doi.org/10.1590/S0102-33062007000400001.

Varela, S. et al. Evaluation of plantation and early development of five alternatives to ponderosa pine in silvopastoral systems in northwest Patagonia, Argentina. Agroforestry Systems, v. 91, n. 5, p. 981-991, 2017. https://doi.org/10.1007/s10457-016-9972-5.

Wilson, O. J. et al. Cold spot microrefugia hold the key to survival for Brazil's critically endangered araucaria tree. Global Change Biology, v. 25, n. 12, p. 4339-4351, 2019. https://doi.org/10.1111/ gcb. 14755 . 